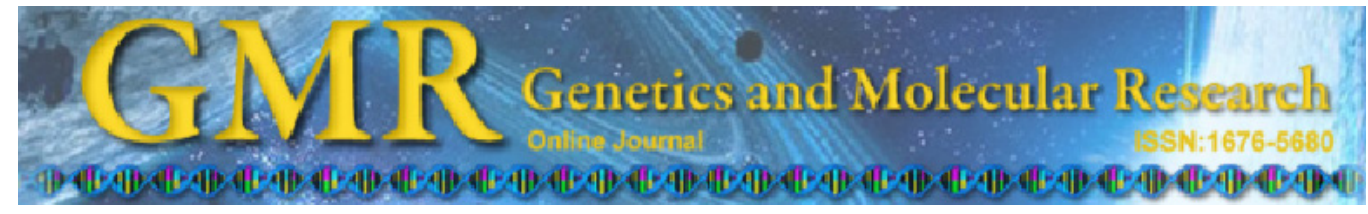

Short Communication

\title{
Isolation and characterization of microsatellite markers for the White Cloud Mountain minnow (Tanichthys albonubes) in wild and cultured populations
}

\author{
J. Zhao ${ }^{1,2}$, D.-Y. Tseng ${ }^{3}$, H.-D. Lin ${ }^{4}$ and X.-T. Lin ${ }^{1}$ \\ ${ }^{1}$ Institute of Hydrobiology, Jinan University, Guangzhou, China \\ ${ }^{2}$ Guangdong Provincial Key Laboratory for Healthy and Safe Aquaculture, \\ Key Laboratory of Ecology and Environment Science in Guangdong \\ Higher Education, School of Life Science, South China Normal University, \\ Guangzhou, China \\ ${ }^{3}$ Department of Biological Sciences and Technology, \\ National University of Tainan, Tainan, Taiwan \\ ${ }^{4}$ The Affiliated School of National Tainan First Senior High School, \\ Tainan, Taiwan \\ Corresponding author: X.-T. Lin \\ E-mail: tlinxt@jnu.edu.cn
}

Genet. Mol. Res. 10 (3): 2223-2229 (2011)

Received July 11, 2011

Accepted September 1, 2011

Published September 27, 2011

DOI http://dx.doi.org/10.4238/vol10-3gmr1556

\begin{abstract}
We developed 12 microsatellite loci for the endangered minnow species, Tanichthys albonubes, using PCR-based isolation of microsatellite arrays. These new markers were tested in 26 individuals from a wild population collected from Guangzhou in China and 26 individuals from a cultured strain. The number of alleles ranged from two to nine and the expected heterozygosity from 0.177 to 0.853 . The wild population had significantly higher allelic richness than the cultured strain, with a mean allelic richness of $5.52($ range $=3.69-8.64)$ and 3.13 (range $=1.99-5.73$ ) for the wild population and the cultured
\end{abstract}


strain, respectively. No evidence of a recent bottleneck was detected in the wild population, but it was found in the cultured strain based on the BOTTLENECK test. These primers can be used to understand the demography and to examine genetic differences between the cultured $T$. albonubes strains and wild populations to help determine conservation and reintroduction strategies.

Key words: Tanichthys albonubes; Microsatellite marker; Bottleneck; Endangered species

The White Cloud Mountain minnow, Tanichthys albonubes Lin, is a small and popular ornamental cyprinid fish, originally found in Guangzhou, China. The wild populations of this species were thought to be extinct because there were no reports of this fish in the wild since 1980. It is a second-class state protected animal in China and classified as "extinct in nature" in the China Red Data Book (Yue and Chen, 1998) and China Species Red List, Vol. II (Wang and Xie, 2009). A wild population was discovered in mountain spring wells in the vicinity of Guangzhou (Liang et al., 2008), and a nature reserve was established for its protection. Tanichthys albonubes has characteristics similar to that of the model species Danio rerio, e.g., small in size, short generation time, laying eggs in batches, and transparent embryos, which render T. albonubes suitable for transgenic research.

Microsatellites are DNA markers that have proven to be highly polymorphic and codominant and have been used to address the genetic diversity and population structure of freshwater fishes (Crooijmans et al., 1997).

These markers have been widely used to determine genetic variation among wild and cultured populations of fish (Was and Wenne, 2002). They are also used to study population bottlenecks (Jarne and Lagoda, 1996) to facilitate specifically breeding programs (Jackson et al., 2003). The aim of this study was to isolate and characterize 12 novel microsatellite loci for the investigation of the genetic structure and bottleneck effect in wild and cultured populations of T. albonubes.

A microsatellite library was constructed using polymerase chain reaction (PCR)based isolation of microsatellite arrays (PIMA) as proposed by Lunt et al. (1999). It takes advantage of the fact that the random amplified polymorphic DNA (RAPD) fragments contain microsatellite repeats more frequently than random genomic clones. The DNA was extracted from fin and/or muscle following the phenol-chloroform protocol. The RAPD-PCR amplifications were performed in a thermal cycler (Bio-Rad) with a reaction mixture $(50 \mu \mathrm{L})$ containing 20-100 ng DNA, $0.2 \mathrm{mM}$ of each dNTP, $2 \mathrm{mM} \mathrm{MgCl}, 0.5 \mathrm{U}$ Taq polymerase (Promega), and 5 pmol RAPD primer. RAPD-PCR products were size-selected to preferentially obtain small fragments (500-1, $200 \mathrm{bp}$ ). Approximately $100 \mathrm{ng}$ PCR product was ligated into a pGEM-T vector (Promega) according to manufacturer instructions, and the ligation mixture was transformed into competent Escherichia coli cells. Clones were screened using microsatellite-specific primers and two vector primers (Lunt et al., 1999). In positive clones, the repeat-specific and vector primers amplified DNA fragments containing microsatellites, whereas no amplification was found in negative clones. Plasmid DNA from positives was purified using the High-Speed Plasmid Mini kit (Geneaid). Both strands of the DNA insert were sequenced with an Applied Biosystems Model 377A automated sequencer (Applied Biosystems). Specific- 
primer pairs were designed according to the nucleotide sequences upstream and downstream of the repetitive DNA using the Primer 3 software (Rozen and Skaletsky, 2000). Preliminary assessment of polymorphism was performed on a few individuals. Reactions were performed in a total volume of $15 \mu \mathrm{L}$ containing $10 \mathrm{ng}$ genomic DNA, $0.2 \mathrm{mM} \mathrm{dNTPs}, 2 \mathrm{mM} \mathrm{MgCl}$, and $0.12 \mu \mathrm{M}$ of each primer. PCRs were as follows: $94^{\circ} \mathrm{C}$ for $4 \mathrm{~min}$ followed by 40 cycles at $94^{\circ} \mathrm{C}$ for $30 \mathrm{~s}, 30$ to $50 \mathrm{~s}$ at primer-specific annealing temperature (Table 1 ), $72^{\circ} \mathrm{C}$ for $45 \mathrm{~s}$, and a final extension step at $72^{\circ} \mathrm{C}$ for $10 \mathrm{~min}$. Electrophoresis was performed in denaturing $6 \%$ polyacrylamide gels using 10-bp ladder for molecular size standard (Invitrogen) to estimate allele sizes via ethidium bromide straining. A total of $52 \mathrm{~T}$. albonubes specimens were collected from a wild population (GM) in Guangzhou, China, and a cultured population (CR) in Taiwan.

Genotype data files were interconverted for the various analytical software programs using CREATE (Coombs et al., 2008) to minimize errors. Arlequin version 3.11 (Excoffier et al., 2005) was used to estimate mean numbers of alleles, observed heterozygosity $\left(H_{\mathrm{O}}\right)$, expected heterozygosity $\left(H_{\mathrm{E}}\right)$, and Hardy-Weinberg equilibrium (HWE) status. Allelic richness and fixation index $\left(F_{\mathrm{ST}}\right)$ (Weir and Cockerham, 1984) were estimated using the FSTAT for Windows version 2.9.3 software (Goudet, 2002). Inbreeding coefficient $\left(F_{\text {IS }}\right)$ (Weir and Cockerham, 1984) and the significance of these values were calculated for each population in GenePop Web Version 4.0.10 (Rousset, 2008). The allelic richness differences between wild and cultured populations were compared using the Wilcoxon signed-rank test (JMP 8, SAS Institute Inc.).

A recent expansion or bottleneck in each population was tested using the version 1.2.02 BOTTLENECK software (Piry et al., 1999), using a coalescent procedure to compare variation (excess or deficiency) in heterozygosity (Cornuet and Luikart, 1996). The observed allele frequency distribution was compared with that of a population in mutation-drift equilibrium assuming the SMM (stepwise mutation model; Kimura and Ohta, 1978) and TPM (two-phase model; Di Rienzo et al., 1994) with 70\% SMM and 30\% infinite allele model. The significance of the test was assessed with sign and Wilcoxon tests. Statistically, the first test offers low power, but the second test displays relatively high statistical power and can be applied with as few as four polymorphic loci and any number of individuals (Cornuet and Luikart, 1996).

Locus designation, GenBank accession number, repeat motif, PCR product size range, and number of alleles for the 12 microsatellite markers are listed in Table 1 . The mean number of alleles was 3.16 and 5.83 in the CR and GM populations, respectively. Allelic richness was calculated to compare the number of alleles in samples of unequal size. The wild population had significantly higher allelic richness than the cultured strain, with an average allelic richness of 5.52 (range $=3.69-8.64$ ) and 3.13 (range $=1.99-5.73$ ) for the wild population and the cultured strain, respectively, which may be caused by hatchery selection and inbreeding (cf. Table 2). $F$-statistics showed significant population differentiation between the cultured strain and wild population $\left(F_{\mathrm{ST}}=0.259 ; \mathrm{P}=0.000\right)$. The strong genetic differentiation observed in this study demonstrates that microsatellite markers can detect population structure in $T$. albonubes and will facilitate population genetic studies including assignment tests, pedigree analysis and mapping studies. Deviations from Hardy-Weinberg expectations of heterozygosity were seen in both wild and cultured populations (Table 2), both exhibiting significant departures $(\mathrm{P}<0.05)$ from HWE for 7 and 5 loci, respectively. The paired-sample $t$-test of $H_{\mathrm{O}}$ and $H_{\mathrm{E}}$ implied that there was no significant difference between wild and cultured populations 


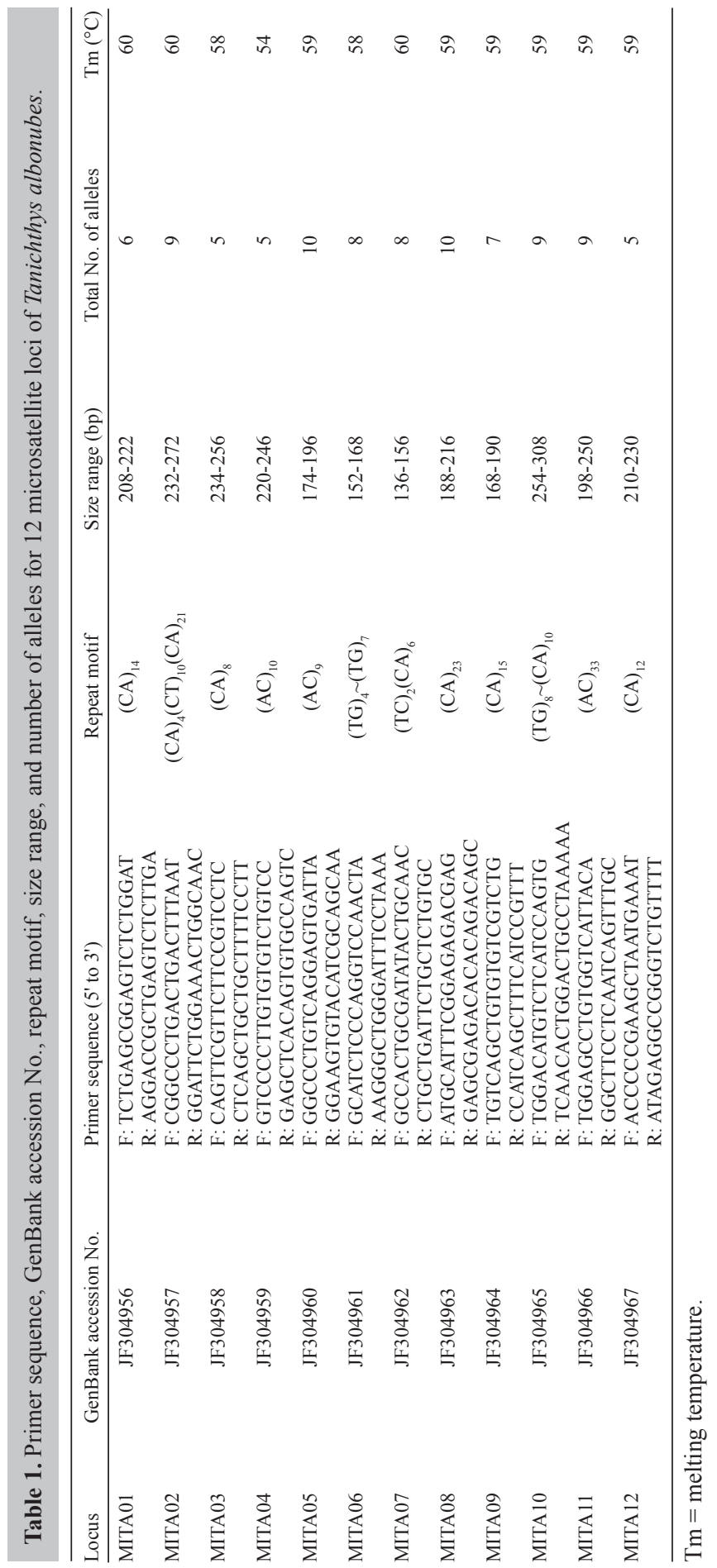




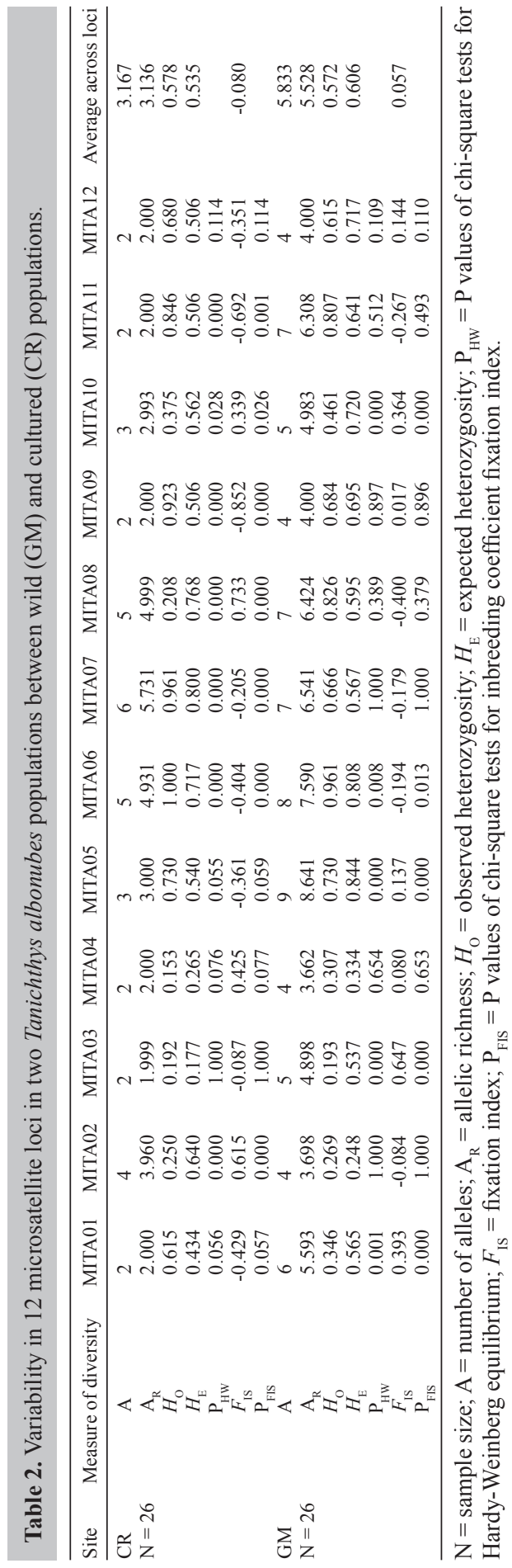


$(\mathrm{P}=0.962$ and 0.349 , respectively). Additionally, the GM and CR populations exhibited significant differences in allelic richness (Wilcoxon signed-rank test, $\mathrm{Z}=2.98702, \mathrm{P}=0.0028$ ), where GM showed a significantly higher value for allelic richness than CR (Table 2). The mean score of GM (16.883) was higher than that of CR (8.1667), but there was no significant difference in overall heterozygosity. Similar results were presented by Norris et al. (1999), indicating that allelic diversity is a more sensitive measure of variability between wild and cultured populations compared to heterozygosity.

The bottleneck test with the SMM and TPM models showed deviations from mutation equilibrium for cultured population (CR) with sign and Wilcoxon tests (Table 3). No evidence of a recent bottleneck was detected in the wild population. The reduced genetic variability that we observed in the cultured strains is probably due to a low number of successful breeders during the establishment of these strains and is similar to a recent bottleneck effect in terms of impact on genetic variability (Allendorf, 1986).

Table 3. Bottleneck results for Tanichthys albonubes from cultured (CR) and wild (GM) populations, showing mode shift and heterozygote excess (significant $\mathrm{P}$ values in bold) from the sign test and the Wilcoxon signed-rank test.

\begin{tabular}{llcr}
\hline Populations & & \multicolumn{2}{c}{ Heterozygote excess P values } \\
\cline { 3 - 4 } & & CR & GM \\
\hline Sign test & SMM & $\mathbf{0 . 0 0 7 4 7}$ & 0.05962 \\
& TPM & $\mathbf{0 . 0 0 4 2 8}$ & 0.16881 \\
Wilcoxon test & SMM & $\mathbf{0 . 0 0 1 2 2}$ & 0.98291 \\
Mode shift & TPM & $\mathbf{0 . 0 0 0 3 7}$ & 0.95386 \\
& & Shifted mode & Normal L-shaped distribution
\end{tabular}

SSM = stepwise mutation model; TPM = two-phase model (70\% SMM and 30\% infinite allele model). Values in boldface type are significant at $\mathrm{P}<0.05$.

This study showed that the 12 microsatellite loci are useful genetic markers to address the genetic difference between the wild and cultured populations, indicating a tendency towards a reduction in variability within the cultured $T$. albonubes strain and an increase in differentiation between the cultured T. albonubes strain and the wild population.

\section{ACKNOWLEDGMENTS}

Research supported by the Project of Science and Technology Research of Guangdong Province (\#2009B060600007) and the National Natural Science Foundation of China (\#30970555). We thank Mr. Yi Zu Sheng of Guangzhou University for providing some specimens of the wild population and Dr. Yu Zi Niu for very helpful advice in preparing the manuscript.

\section{REFERENCES}

Allendorf FW (1986). Genetic drift and the loss of alleles versus heterozygosity. Zoo Biol. 5: 181-190.

Coombs JA, Letcher BH and Nislow KH (2008). Create: a software to create input files from diploid genotype data for 52 genetic software programs. Mol. Ecol. Res. 8: 578-580.

Cornuet JM and Luikart G (1996). Description and power analysis of two tests for detecting recent population bottlenecks from allele frequency data. Genetics 144: 2001-2014. 
Crooijmans RPMA, Van Der Poel JJ, Groenen MAM, Bierbooms VAF, et al. (1997). Microsatellite markers in common carp (Cyprinus carpio). Anim. Genet. 28: 129-134.

Di Rienzo A, Peterson AC, Garza JC, Valdes AM, et al. (1994). Mutational processes of simple-sequence repeat loci in human populations. Proc. Natl. Acad. Sci. U. S. A. 91:3166-3170.

Excoffier L, Laval G and Schneider S (2005). Arlequin (version 3.0): an integrated software package for population genetics data analysis. Evol. Bioinform. Online 1: 47-50.

Goudet J (2002). A Program to Estimate and Test Gene Diversities and Fixation Indices (Version 2.9.3). Institute of Ecology, University of Lausanne, Lausanne.

Jackson TR, Martin-Robichaud DJ and Reith ME (2003). Application of DNA markers to the management of Atlantic halibut (Hippoglossus hippoglossus) broodstock. Aquaculture 220: 245-259.

Jarne P and Lagoda PJL (1996). Microsatellites, from molecules to population and back. Trends Ecol. Evol. 11: 424-429.

Kimura M and Ohta T (1978). Stepwise mutation model and distribution of allelic frequencies in a finite population. Proc. Natl. Acad. Sci. U. S. A. 75: 2868-2872.

Liang XF, Chen GZ, Chen XL and Yue PQ (2008). Threatened fishes of the world: Tanichthys albonubes Lin 1932 (Cyprinidae). Environ. Biol. Fish. 82: 177-178.

Lunt DH, Hutchinson WF and Carvalho GR (1999). An efficient method for PCR-based isolation of microsatellite arrays (PIMA). Mol. Ecol. 8: 891-894.

Norris AT, Bradley DG and Cunningham EP (1999). Microsatellite genetic variation between and within farmed and wild Atlantic salmon (Salmo salar) populations. Aquaculture 180: 247-264.

Piry S, Luikart G and Cornuet JM (1999). Bottleneck 1202: a computer program for detecting recent reduction in the effective population size using allele frequency data. J. Hered. 90: 502-503.

Rousset F (2008). Genepop'007: a complete reimplementation of the Genepop software for Windows and Linux. Mol. Ecol. Res. 8: 103-106.

Rozen S and Skaletsky HJ (2000). Primer3 on the WWW for General Users and for Biologist Programmers. In: Bioinformatics Methods and Protocols, Methods in Molecular Biology (Misener S and Krawetz SA, eds.). Humana Press, Totowa, 365-386.

Wang S and Xie Y (2009). China Species Red List: Vertebrate. Vol. II. Higher Education Press, Beijing, 189.

Was A and Wenne R (2002). Genetic differentiation in hatchery and wild sea trout (Salmo trutta) in the southern Baltic at microsatellite loci. Aquaculture 204: 493-506.

Weir BS and Cockerham CC (1984). Estimating F-statistics for the analysis of population structure. Evolution 38: 13581370.

Yue PQ and Chen YY (1998). China Red Data Book of Endangered Animals. In: Pisces (Wang S, ed.). Science Press, Beijing, 68-70. 